\title{
Yüz İfadesini Algılayarak Kullanıcının Ruh Haline Göre İçerik Öneren Mobil Uygulama
}

\author{
İsmail Gündüz ${ }^{1}$, Özgün Y1lmaz ${ }^{2 *}$ \\ ${ }^{1}$ Ege Üniversitesi, Mühendislik Fakültesi, Bilgisayar Mühendisliği Bölümü, ̇̇zmir, Türkiye, (ORCID: 0000-0003-4840-0612), ismail.gunduz.1999@_gmail.com \\ $2^{*}$ Ege Üniversitesi, Mühendislik Fakültesi, Bilgisayar Mühendisliği Bölümü, İzmir, Türkiye (ORCID: 0000-0002-4394-4031), ozgun.yilmaz@ege.edu.tr
}

(1st International Conference on Applied Engineering and Natural Sciences ICAENS 2021, November 1-3, 2021)

(DOI: 10.31590 /ejosat.994802)

ATIF/REFERENCE: Gündüz, İ., Yılmaz, Ö. (2021). Yüz İfadesini Algılayarak Kullanıcının Ruh Haline Göre İçerik Öneren Mobil Uygulama. Avrupa Bilim ve Teknoloji Dergisi, (28), 192-197.

\section{Öz}

Günümüzde insanlar, boş zamanlarını değerlendirmek için akıllı cihazları üzerinden dijital içerikler tüketmektedir. Ancak bazen kullanıcılar o anki ruh durumlarına göre bir film, dizi veya video izlemek ya da müzik dinlemek isteyebilir. Bu çalışmada, bu soruna çözüm olarak geliştirilen mobil uygulama anlatılmaktadır. Hedef cihaz olarak da hemen hemen herkesin sahip olduğu akıllı telefonlar seçilmiştir. Mobil uygulamada, kullanıcı rastgele olarak veya o anki ruh durumunu kendisi belirterek veya kullanıcının yüz ifadesine göre içerik önerileri alabilir. Yüz ifadesine göre içerik önerisinde bulunmak amacıyla, yapay zeka ve görüntü işleme kullanılarak, akıllı telefonun kamerasından kullanıcının anlık yüz ifadesi elde edilerek kullanıcının ruh hali tahmin edilir ve kullanıcıya bu ruh haline uygun dijital içerik önerilir. Ayrıca, hangi duyguya karşılık hangi içerik türünün içinden seçim yapılacă̆ı, sistem yöneticisi tarafından belirlenebilir.

\section{Mobile Application for Recommending Content Based on User's Mood by Detecting Facial Expression}

\begin{abstract}
Nowadays, people consume digital content on their smart devices to spend their free time. However, sometimes users might want to watch movies, TV series, videos or listen to music according to their current emotional state. In this paper, a mobile application is proposed as a solution to this problem. Since almost everyone owns a smartphone, smartphones have been determined as the target device. Via the mobile application, the users can receive content recommendations randomly or by entering their current mood or based on the user's facial expression. In order to recommend content based on facial expression, the user's mood is predicted by using artificial intelligence and image processing after the user's instant facial expression is obtained from the smartphone's camera, and digital content suitable for this mood is recommended to the user. In addition, the system administrator can determine which content type to choose against which emotion.
\end{abstract}

Keywords: Digital content, Artificial intelligence, Image processing, Mood, Smart recommendation.

\footnotetext{
*Sorumlu Yazar: ozgun.yilmaz@ege.edu.tr
} 


\section{Giriş}

Gelecekte teknolojinin, günümüzde olduğundan daha yaygın olacağı beklenmektedir. Gelişen teknolojilerle birlikte insanların alışkanlıkları da değişiklik göstermiştir. Örneğin sinema salonları evimize kadar girmiştir. Artık izlemek istediğimiz film kumandamızın birkaç tuş uzağındadır. Hatta bazı teknolojiler aracılığıyla, kumandaya ihtiyaç bile duyulmamaktadır. Kullanıcı verdiği sesli komutlar aracılığıyla sistemi yönetebilmektedir. İstediğimiz filmi seçmek yerine sistem bizim beğeneceğimizi tahmin ettiği filmi gösterebilmektedir. Bunu yapay zeka ve derin öğrenme tekniklerini kullanarak yapmaktadır. Ancak insanların halihazırda kullandığı bu sistemler duygularımızı işin içine katmamaktadır. Duyguları da dikkate alarak kullanıcılara daha uygun öneriler sunulabilir (Babanne, Borgaonkar, Katta, Kudale, \& Deshpande, 2020; Mariappan, Suk, \& Prabhakaran, 2012).

Duygularımız, o anda yaptığımız eylemleri büyük ölçüde etkiler. Bu sebeple bir insan, benzer durumlarda farklı ruh hali içerisinde bulunduğu takdirde birbirine tamamen zıt eylemler gerçekleştirebilir (Metilda Florence \& Uma, 2020; Sharma, 2020). Genellikle komedi filmi izleyen bir kullanıcıya "akıllı" sistemler komedi filmi önerecektir. Ancak bu kullanıcının mutsuz bir ruh halinde olduğunu varsayarsak, kullanıcı komedi filmi izlemek istemeyebilir. Bir dram filmi önermek kullanıcının ağlama ihtiyacını gidermesine yardımcı olabilir. Veya gülücük saçan bir kullanıcı pek izlemiyor olsa da bir komedi filmi aracılığıyla daha da mutlu olabilir.

Bu çalışmada, kullanıcılara o anki duygularına uygun dijital içerik önerilmesi hedeflenmektedir. Bu bağlamda hedef kitle, dijital içerik tüketen tüm kullanıcılardır. Bu da günümüzde hemen hemen herkes anlamına gelmektedir.

Çalışma, Android işletim sistemini çalıştıran mobil cihazlar için tasarlanmış ve geliştirilmiştir. Son araştırmalara göre Android'in küresel olarak \%87 gibi bir oranla en popüler işletim sistemi olması (Statista, 2019), işletim sistemi konusunda bu seçimin yapılmasının en önemli sebebidir. Geliştirim aşamasında Android geliştirmede önemli bir rol sahibi olan Java programlama dili kullanılmıştır.

$\mathrm{Bu}$ çalışma, kullanıcıların boş zamanlarını hem sevebilecekleri hem de o anki duygu durumlarına uygun içeriklerle harcamaları, teknolojinin günlük hayatta etkili kullanımına bir örnek olması açısından önemlidir. Aynı zamanda kaliteli içerik önerileriyle kullanıcının içerik arama esnasında kaybedeceği zamanı da en aza indirme gibi bir avantajı da bulunmaktadır. Geliştirilen uygulamaya "Moodie" ismi verilmiştir. İngilizce ruh hali anlamına gelen "mood" ve film anlamına gelen "movie" kelimelerinin birleşiminden türetilmiştir.

\section{2. İlgili Çalışmalar}

Bu bölümde halihazırda bu projenin amacına yönelik olarak üretilmiş ve kullanıcılara sunulmuş uygulamalardan ve web sitelerinden bahsedilmektedir.

\subsection{A Good Movie To Watch}

A Good Movie To Watch (A Good Movie to Watch, 2021), kendi geliştiricileri tarafından "Çok beğenilen ancak az bilinen filmleri ve dizileri önerir." cümlesiyle tanımlanmıştır. Belirtilene göre \%70'in üzerinde izleyici ve eleştirmen puanına sahip içerikler barındırır. Belli bir algoritma aracılığıyla çalışmayan bu platformda öneriler tamamıyla insanlar tarafindan yapılmaktadır. Yani bu sitede gördüğünüz bir filmi, siteye katkıda bulunan herhangi bir kişinin izlediğini ve bu kişinin filme kefil olduğunu anlayabiliriz. Algoritma kullanılmamasının sebebi olarak geliştiriciler, algoritmaların geçmiş tercihlere göre içerik önereceğini öne sürmektedir (A Good Movie to Watch, 2021).

A Good Movie To Watch, komik, romantik, depresif gibi ruh hallerine yönelik öneriler yapıyor. Bu bildiride anlatılan çalışma ile aradaki en büyük fark ruh halinin yalnızca kullanıcı tarafından seçilmesi. Çalışmada ise ruh hali; kullanıcının seçimine bırakılabildiği gibi, görüntü işleme aracılığıyla kullanıcının yüz ifadesi algılanarak belirlenip ona göre içerik önerisi getirilmektedir. Bununla birlikte A Good Movie To Watch, kullanıcılarına herhangi bir mobil uygulama sunmuyor. Yalnızca web sitesi üzerinden hizmet veriyor (A Good Movie to Watch, 2021).

\subsection{Flickseeker}

Flickseeker (Flickseeker, 2021), A Good Movie To Watch ile oldukça benzer bir arayüze sahip olmakla birlikte yalnızca film önerisi sunar. Önerilen filmler eleştirmenlerin ya da diğer profesyonellerin verdiği puanlara değil, diğer Flickseeker kullanıcılarının his ve yorumlarına bağlı olarak seçilir. Film etiketleme görevi, filmi izleyen kullanıcılara verilir. Flickseeker ekibinin düşüncesine göre bu, Flickseeker platformunu benzersiz ve etkili k1lmaktadır (Flickseeker, 2021).

Flickseeker sitesinde tam 50 adet his yer almaktadır. Bu da $\mathrm{A}$ Good Movie To Watch platformundaki his sayısının hemen hemen 2 katına eşittir. Kullanıcılar Flickseeker'da film ararken birden fazla his işaretlemesi yapabilir. Yani aynı anda hem dram hem de gerçek hayat hikayesi içeren filmler listelenebilir. Tüm bunlar kullanıcıların filme verdikleri etiketler sayesinde gerçekleşir (Flickseeker, 2021).

$\mathrm{Bu}$ bildiride bahsedilen çalışmada ise, ruh hali için kullanıcının o anki yüz ifadesi kullanılabildiği gibi kullanıcı ruh halini kendi de seçebilmektedir. Ancak Flickseeker'da da A Good Movie To Watch'takine benzer şekilde ruh hali seçimi yalnızca kullanıcı tarafindan elle yapılabilmektedir. Yine aynı şekilde Flickseeker, kullanıcılarına yalnızca web sitesi üzerinden ulaşmaktadır.

\subsection{FEELM}

FEELM (Feelm, 2021), kendi deyimleriyle, insan gücüyle çalışan bir keşif platformudur. Kullanıcılarının film arama şeklini baştan aşağı değiştirmeyi amaçlamaktadır ve Flickseeker'a benzer şekilde bilgisayar algoritmalarını değil, insan gücünü tercih etmektedir. FEELM'in sunduğu arama yöntemi kategorilerin ve basit duyguların tamamen ötesine geçer. FEELM platformunda film ararken aksiyon, drama gibi kategoriler ve mutlu, depresif gibi ruh halleri yerini "geçmişle yüzleşiyormuş gibi hissediyorum" ya da "ateşle oynuyormuş gibi hissediyorum" gibi daha kompleks ifadelere birakmaktadır (Feelm, 2021).

FEELM platformunda yalnızca film önerisinde bulunulmamaktadır. Aynı zamanda önerilen filmin konusu, fragmanı, izleyici yorumları, bulunduğu dijital platformlar gibi filmseverler için büyük önem taşıyan bilgileri kullanıcılara sunar (Feelm, 2021).

FEELM, önceki iki örnekten farklı olarak kullanıcılarına mobil uygulama desteği sunmaktadır. Ancak bu uygulama yalnızca iOS işletim sistemi ile çalışan cihazlar ile uyumludur. 


\subsection{Charmy}

Charmy (Charmy, 2021), temelde bir sosyal medya platformudur. Kullanıcıların müzik, kitap, film ve diziler hakkında birbirleriyle etkileşim içerisinde bulunmasını amaçlamaktadır. Bunun yanı sıra kullanıcılarına seçilen tür ya da önceden izlenip beğenilen film, dizi ve müziklere bağlı olarak liste oluşturan bir sanal asistan içermektedir. Benzer zevklere sahip kullanıcıları zaman akışında bir araya getirmekte ve bu kullanıcılar birbirlerine yeni önerilerde bulunarak etkileşime girmektedir. Charmy, hem bilgisayar algoritmalarını hem de insan etkileşiminin gücünü kullanan bir platformdur. $\mathrm{Bu}$ da kendisini diğer örneklerden ayıran önemli bir unsur olarak dikkat çekmektedir (Charmy, 2021).

Charmy Asistan ile film ve dizi önerisi almak için kullanıcının ilk olarak daha önceden izleyip beğenmiş olduğu film ve dizileri seçmesi gerekmektedir. Sonrasında tür belirleyerek ya da yapay zeka kullanan asistan aracılığıyla liste oluşturulmaktadır (Charmy, 2021).

Müzik önerilerinde film ve diziden farklı bir nokta vardır ve bu nokta Charmy'i Moodie'ye yaklaştıran bir özelliktir. Müzik önerisi almak için film ve dizide olduğu gibi tür seçimi ya da otomatik liste özellikleri kullanılabilmektedir. Bunun yanı sıra kullanıcı o anda çekeceği bir özçekim ile ruh halinin Charmy Asistan tarafindan belirlenmesini isteyebilmektedir. Charmy Asistan, çekilen fotoğraftan ruh halini algıliyor ve buna göre bir müzik önerisinde bulunuyor (Charmy, 2021).

\section{Materyal ve Yöntem}

$\mathrm{Bu}$ çalışmada anlatılan mobil uygulama, Android tabanlı mobil cihazlarda çalışacak şekilde Java programlama dili ile geliştirilmiştir. $\mathrm{Bu}$ geliştirim esnasında nesne tabanlı programlama ilkelerine bağlı kalınmıştır. Geliştirim için Google'ın entegre geliştirme ortamı olan Android Studio IDE'si kullanılmıştır.

İçeriklere ait bilgiler, Google Cloud üzerinde çalışan bulut tabanlı bir veri tabanı servisi olan Google Cloud SQL ile saklanmaktadır. Veri tabanının bulut tabanlı olması sayesinde veri tabanına yeni içerikler eklendiğinde veya var olan içeriklerin bilgileri güncellendiğinde kullanıcının hiçbir ek işlem yapmadan bu içeriklere ve güncel bilgilere erişmesi sağlanmış olur.

Uygulamanın görüntü işleme kısmında yüz ifadesini tanımlayabilmek için FER (Shenk, 2021) kütüphanesini kullanan bir Python servisi oluşturulmuştur. Bu Python servisi Flask ile bir web servise dönüştürülmüş ve bu sayede mobil uygulama üzerinden uzaktan erişim imkanı sağlanmıştır. Mobil uygulama ile web servis arasındaki iletişim HTTP POST metodu üzerinden sağlanmaktadır. Gönderilen veri Base64 kodlama şeması kullanılarak şifrelenip POST metoduna iletilmektedir.

\subsection{Android}

Android, Google ve Open Handset Alliance tarafindan geliştirilen, mobil cihazları hedef alan, Linux tabanlı, ücretsiz ve açık kaynak kodlu bir işletim sistemidir. Açık kaynak kodlu olmasına rağmen ufak ama önemli bir bölümü Google tarafından kapalı tutulmaktadır (Amadeo, 2018). Linux çekirdeği üzerine inşa edilen Android'de uygulama yazılımları, Apache Harmony üzerine kurulu Java uyumlu kütüphaneleri içine alan uygulama iskeleti üzerinden çalışmaktadır. Android, derlenmiş Java kodunu çalıştırmak için dinamik çevirmeli Android Runtime (ART) kullanır (Android, 2021b).

Uygulamalar genellikle Android SDK aracılığıyla Java ya da Kotlin programlama dili kullanılarak geliştirilir. Bir SDK, belli bir platform için uygulama üretmeyi sağlayan yazılım geliştirme araçlarından oluşan yazılımdır. Android SDK geliştiricilere kapsamlı bir geliştirme aracı seti sunar. Bunların arasında hata ayıklayıcı, kitaplıklar, belgeler, örnek kodlar ve öğreticiler bulunmaktadır (Android, 2021a). Android SDK, Windows, MacOS ve Linux ile uyumludur. Böylece geliştiriciler uygulamalarını bu platformların herhangi birinde geliştirebilirler.

\subsection{Google Cloud SQL}

Google tarafindan sunulan Google Cloud, Google'ın Arama, Gmail, Drive ve YouTube gibi son kullanıcı ürünleri için dahili olarak kullandığı altyapı üzerinde çalışan bir bulut bilişim hizmetleri paketidir (Google Inc., 2021c). Kullanıcılarına basit web sitelerinden karmaşık uygulamalara kadar birçok çeşitte yazılım geliştirme imkanı sağlar (Google Inc., 2021a). Google Cloud; IaaS (Infrastructure as a Service), PaaS (Platform as a Service) ve sunucusuz bilgi işlem ortamları sunar.

Google Cloud SQL, MySQL, PostgreSQL ve SQL Server için tam olarak yönetilebilen ilişkisel veri tabanı hizmetidir (Google Inc., 2021b). Veri tabanının güvenilir, güvenli ve ölçeklenebilir olmasını otomatik olarak gerçekleştirir. Kurulumu, kullanımı, yönetimi ve bakımı kolaydır. Cloud SQL kullanıcının konumunu gözetmeksizin dünyanın her yerinde $\% 99,95$ 'in üzerinde bir kullanılabilirlik sağlar. Tüm bunlarla birlikte yedekleme, çoğaltma, şifreleme ve kapasite artırma işlemlerini otomatik olarak yapabilir.

\subsection{Görüntü İşleme}

İki boyutlu bir görüntünün birtakım bilgisayar algoritmaları tarafından işlenerek istenen hale getirilmesine "Görüntü İşleme" denir. Görüntü işleme teknolojisi sayesinde kullanıcının elinde bulunan her görüntü kullanım amacına uygun olacak şekilde özelleştirilebilir (Çümen, 2020). Görüntü işleme ile görüntü iyileştirme, görüntü analizi, kenar belirleme, bölütleme, tanıma gibi işlemler kolayca yapılabilir duruma gelmiştir. Günümüzde güvenlik, trafik, savunma sanayi ve tıp başta olmak üzere çokça alanda kullanılmaktadır.

\subsection{FER}

FER (Face Emotion Recognizer), Justin Shenk tarafindan geliştirilen bir Python kütüphanesidir. Keras modelini paketler. Kütüphane içeriğinde HDF5 uzantılı bir dosya bulunmaktadır (Shenk, 2021). Model, bu dosyaya kaydedilen ağırlıklara sahip bir evrişimli sinir ağıdır. Modelde yüz algılama işlemi varsayılan olarak OpenCV'nin Haar Cascade sinıflandırıcısı kullanılarak gerçekleştirilmektedir. Daha doğru ve etkili sonuçlar elde edebilmek için kullanıcılara MTCNN (Multi-task Cascaded Convolutional Networks) ağını kullanma imkanı da tanınmıştır.

\subsection{Flask}

Flask, Python ile geliştirilmiş bir web çerçevesidir. Belirli araçlar veya kitaplıklar gerektirmez. Bu nedenle mikro çerçeve (micro framework) olarak sınıflandırılır. Kullanıcılara geliştirme sunucusu ve hata ayıklayıcı, birim testi için bütünleşmiş destek, güvenli çerez desteği, kapsamlı belgeler ve Google App Engine uyumluluğu gibi birçok özellik sağlar (Flask, 2021). 


\section{Moodie}

Geliştirilen sistemin mimarisi Şekil 1'de görülmektedir. Gerekli analizler yapıldıktan sonra uygulamanın geliştirilmesine veri tabanının oluşturulmasıyla başlanmıştır. Veri tabanına internet üzerinden global bir şekilde erişilebilmesi açısından bulut bilişim hizmetlerinin kullanılması uygun bulunmuştur. $\mathrm{Bu}$ iş için seçilen bulut bilişim platformu, Google Cloud olmuştur. Google Cloud'un sunmuş olduğu Cloud SQL servisi üzerinde MySQL tabanlı bir veri tabanı yaratılmış, içerisine uygulamanın kullanacağı tablolar eklenmiştir. Daha sonra ücretsiz API desteği sunan TheMovieDB (TMDB, 2021) sitesinden alınan API anahtarı ile Moodie veri tabanına aktarılmak üzere birçok film ve bu filmlerle ilgili bilgiler elde edilmiştir.

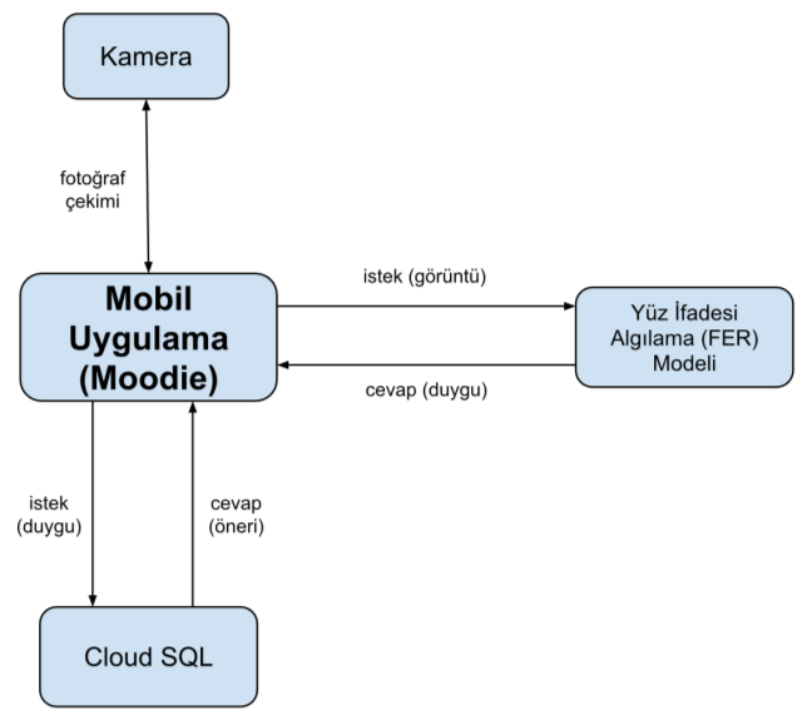

Şekil 1. Sistem mimarisi
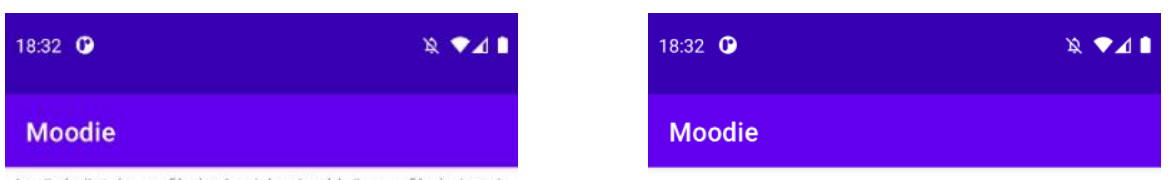
Aşağıda listelenen filmlerden izlemis olduğunuz filmleri seçin
ve ileri butonunu tiklayın. Filmler hakkında daha fazla bilgi için

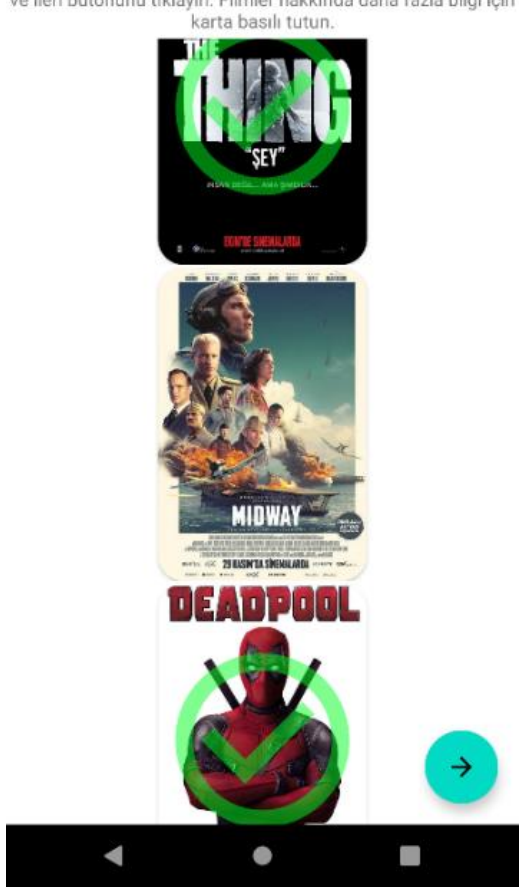

Şekil 2. İzlenen filmleri seçme ekranı
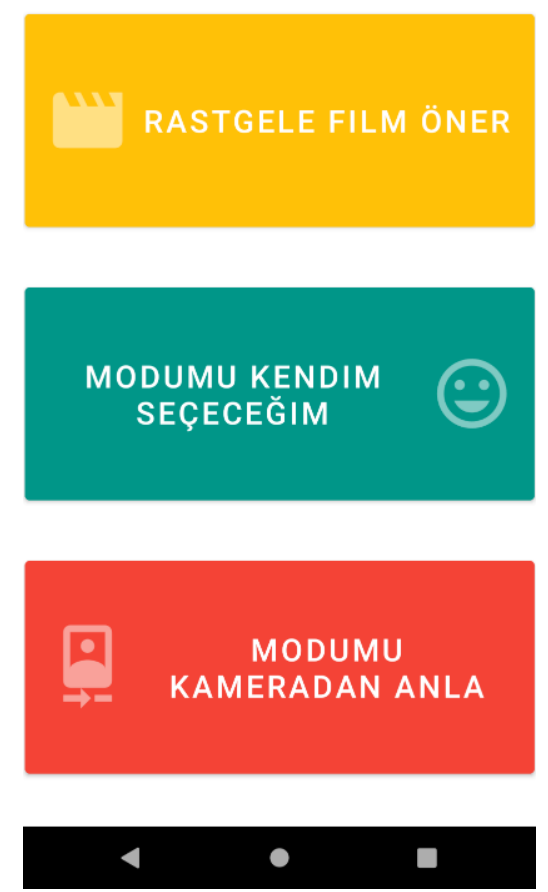

Şekil 3. Moodie ana ekranı
Veri tabanında duyguların filmlerle eşleştirilmesi yerine türlerle eşleştirilmesi daha uygun bulunmuştur. $\mathrm{Bu}$ sayede veri tabanının daha az yer kaplaması ve daha az masrafa yol açması sağlanmıştır. Sorguların daha hızlı çalışacak olması da son kullanıcı tarafındaki önemli avantajlardan biridir.

FER modeli, Flask tabanlı bir Python kodu üzerinde çalışmaktadır. Uygulama, Flask'ta tanımlanan bir web adresine HTTP POST metodu aracılığıyla görüntünün kodlanmış halini iletmektedir. Model ise POST metodundan gelen bu argümanı okuyup Python'ın hazır kütüphanelerinden olan Base64 kütüphanesi ile kodlanmış veriyi çözerek işleme başlamaktadır. FER kütüphanesinin varsayılan ayarlarında yüz algılama için Haar Cascade sınıflandırıcısı kullanılmasına rağmen daha yüksek başarı sağlayabilmek amacıyla modelde MTCNN aktif hale getirilmiştir. Analiz edilen yüz ifadesi geri döndürülerek uygulama ile model arasındaki iletişim tamamlanmış olur.

Geliştirilen kullanıcı arayüzünün kullanıcı dostu olması amaçlanmıştır. $\mathrm{Bu}$ nedenle basit ve anlaşılır bir arayüz hazırlanmıştır.

Moodie, kendisiyle aynı amacı taşıyan uygulamalara göre daha da geliştirilebilir özelliklere sahiptir. Her kullanıcının farklı bir film tercihi bulunabilir. Moodie, veri tabanındaki eşleşmeye bağlı olarak ruh haline göre film türü önerisinde bulunmaktadır. Üzgün kullanıcıya dram filmi önerilmesi buna bir örnektir. Bunun sebebi Moodie'nin, kullanıcıların duygularını yoğun bir şekilde yaşamalarını hedeflemesidir. Ancak her kullanıcının talebi bu yönde olmayabilir. Halihazırda üzgün bir kullanıcı komedi filmi izleyerek mutlu bir ruh haline bürünmek isteyebilir. Moodie'ye her duygu için getirilebilecek "mutluyken ne izlersin?" gibi bir özellik sayesinde öneriler, kullanıcılar için özelleştirilebilir hale getirilebilir.

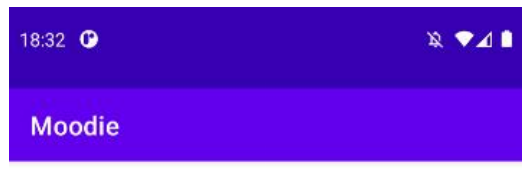

Donnybrook

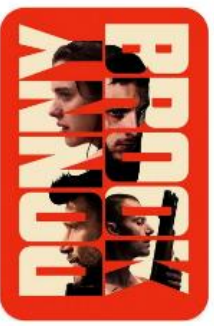

Oyuncular

Jamie Bell

Michael Agee

Adam Bartley

Yönetmen

Tim Sutton

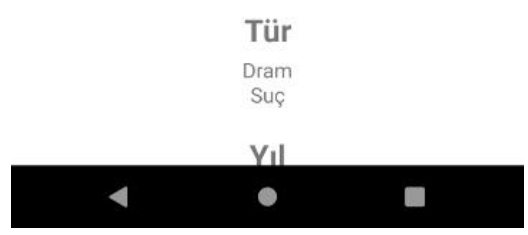

Şekil 4. Film bilgi ekranı 


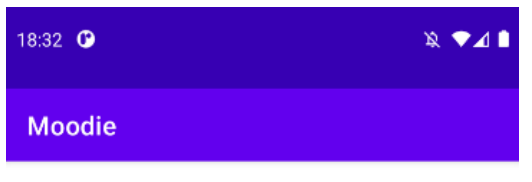

\section{MUTLU}

\section{ÜZGÜN}

\section{KIZGIN}

\section{NÖTR}

\section{KORKMUS}

\section{IĞRENMIŞ}

\section{ŞAŞKIN}

\section{4}
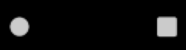

Şekil 5. Ruh hali seçme ekranı

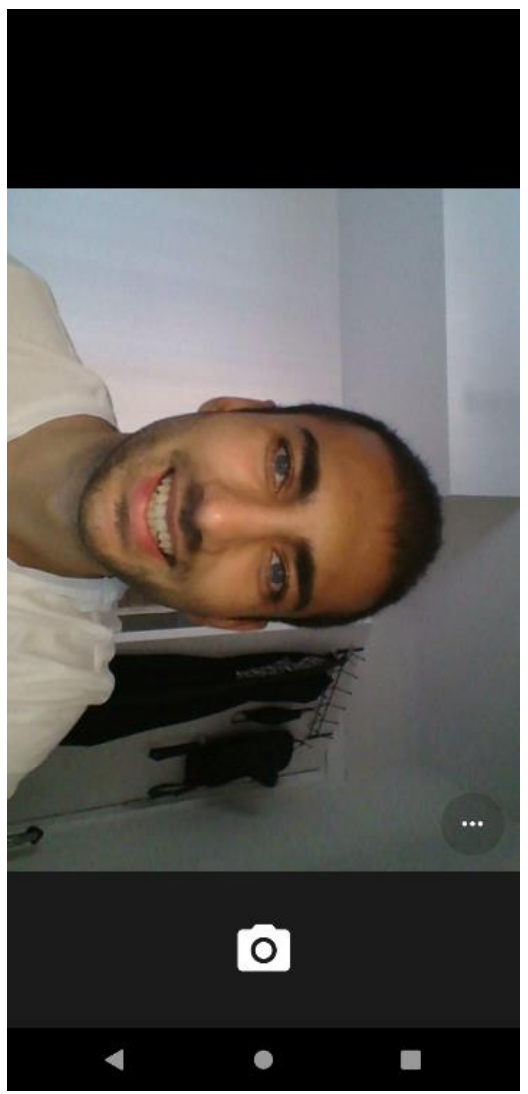

Şekil 6. FER modeline gönderilen görüntü

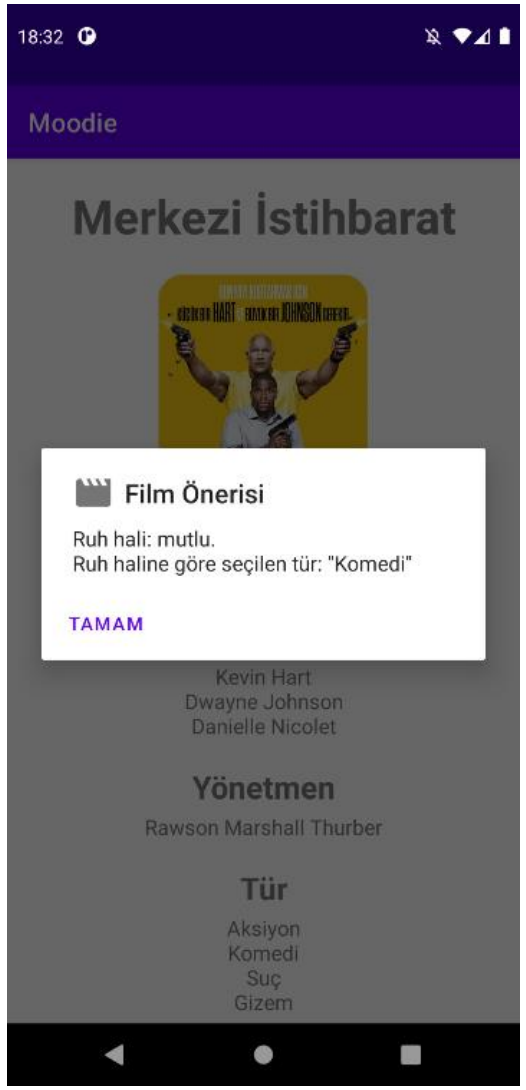

Şekil 7. FER modelinden gelen sonuca göre önerilen tür bilgisi

\section{Durum Çalıșması}

Bu bölümde, geliştirilen mobil uygulamanın kullanımı örnek senaryolar ile anlatılmaktadır.

İlk çalıştırma sırasında uygulama, kullanıcıdan kamera kullanma izni ister. Şekil 2'de görülmekte olan izlenen filmleri seçme ekranında sade bir görüntü elde edilebilmesi açısından yalnızca film afişleri bulunmaktadır. Karmaşık, anlaşılamayan veya başka filmlerle karıştırılabilecek afişlere sahip filmlerin bulunma ihtimaline karşın kullanıcılara bir bilgi kutucuğu da sunulmuştur. Kullanıcıların bu bilgi kutucuğuna erişebilmeleri için ilgili filmin afişine basılı tutmaları yeterlidir. İzlenebilecek bu yol, kullanıcılara bir yardım metni aracılığıyla aktarılmaktadır.

Şekil 3'te görülmekte olan uygulamanın ana ekranı oldukça sade bir görünüme sahiptir. Ana ekranda farklı renkte 3 buton bulunmaktadır. Kullanıcı istediği işlemi rahatlıkla seçebilir.

Seçilebilecek ilk işlem rastgele film önerisi almaktır. Arka planda gerçekleşen işlemlerin ardından, kullanıcı Şekil 4'te görülen filmin bilgi ekranına yönlendirilir. $\mathrm{Bu}$ ekranda filmin afişi, adı, başrolleri, yönetmeni, türleri, yılı ve ülkesi yer almaktadır. $\mathrm{Bu}$ bilgi ekranı standarttır ve diğer 2 işlemin sonucunda da kullanıcının karşısına çıkar.

Ana ekrandaki bir diğer işlem ruh hali seçmektir. Bu seçenek seçildikten sonra kullanıcı Şekil 5'te görülen mutlu, üzgün, kızgın, nötr, korkmuş, iğrenmiş ve şaşkın olmak üzere FER modeli tarafından desteklenen 7 duyguyu görebilmektedir. $\mathrm{Bu}$ duygular arasında seçim yapan kullanıcı tercih ettiği duyguya bağlı olarak seçilen film türü hakkında bilgilendirilir. Daha sonra filmin bilgi ekranıyla karşılaşmaktadır.

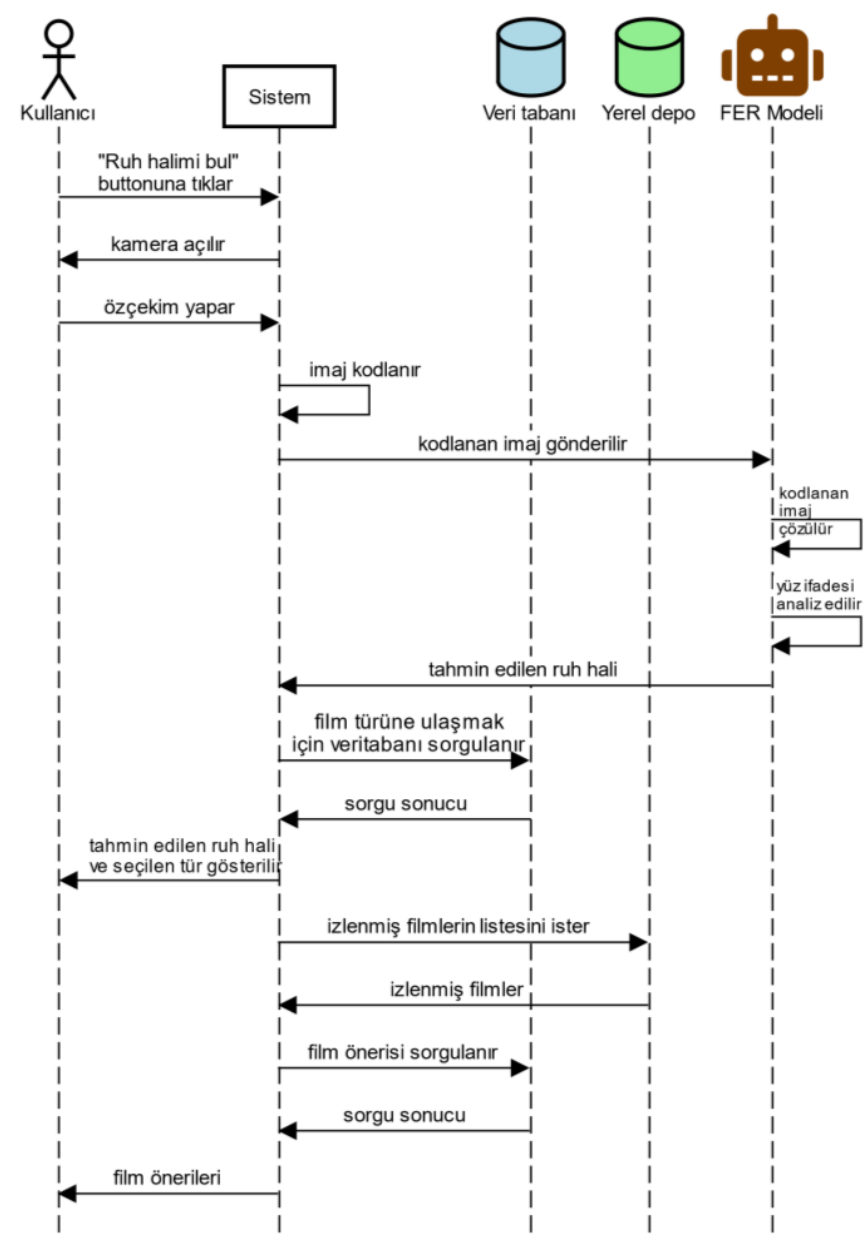

Şekil 8 Kullanıcı ve sistem arasındaki etkileşim 
Moodie'nin son işlemi, aynı zamanda asıl işlevi olan kameradan ruh hali algılamadır. Daha önceden kamera izni verilmemişse bu izin yeniden istenir ve kamera açılır. Şekil 6'da görüldüğü gibi kullanıcı bir özçekim yapar ve bu özçekimi onaylar. Sistem, yapılan özçekimi Base64 kullanarak kodladıktan sonra FER modele iletir. FER modelinden gelen sonuca göre ilgili türdeki bir film Şekil 7'de görüldüğü gibi kullanıcıya önerilir. Seçilen filmin bilgi ekranı kullanıcıya gösterilir. Kameradan ruh hali algılama ve film önerisinde bulunma işleminin gerçekleştirilmesi Şekil 8'de etkileşim diyagramı ile gösterilmiştir.

\section{Sonuç}

Bu çalışmada, kullanıcılara, duygu ve ruh hallerine uygun dizi, film ve müzik önerileri yapılması hedeflenmektedir. Özellikle günümüzde yüksek bir hızla artan dijital içerikler arasında tercih yapmak oldukça zorlaşmıştır. Moodie ile hem ruh haline uygun içerikler izlenebilir, hem de içerik seçme aşamasında kaybedilen süreler telafi edilebilir.

Moodie bu sektörde ortaya atılan ilk uygulama olmamakla beraber diğer uygulamalara göre birtakım farklılıklar da içermektedir. Bazı platformlar yalnızca ruh hali seçimi, bazı platformlar yalnızca rastgele öneriler sunarken Moodie bu ikisinin yanında bir de yüz ifadesinden ruh hali algılama özelliğini eklemiştir.

Moodie'nin artılarından bir diğeri ise içeriklerin geliştirici tarafından kontrol edilebiliyor olmasıdır. $\mathrm{Bu}$ sayede içerik kalitesinin düşmesinin önüne geçilebilir. Düşük puanlı ya da gereğinden fazla şiddet içeren filmler gibi çoğu kullanıcının izlemekten kaçınacağı içeriklerin veri tabanında yer almaması, bu içeriklerin kullanıcılara önerilmeyeceği anlamına gelmektedir. Bunun yerine klasikleşmiş eserlerin ya da önceden beğenilen bir filmin yeni çıkmış devam filminin veri tabanında bulunması içerik kalitesini artırabilecek etkenlerdir.

\section{Kaynakça}

A Good Movie to Watch. (2021). About - A Good Movie To Watch. Retrieved from https://agoodmovietowatch.com/about/

Amadeo, R. (2018). Google's iron grip on Android: Controlling open source by any means necessary. Retrieved from https://arstechnica.com/gadgets/2018/07/googles-iron-gripon-android-controlling-open-source-by-any-meansnecessary/

Android. (2021a). Android Platform. Retrieved from https://developer.android.com/about

Android. (2021b). Application Fundamentals - Android Developers. Retrieved from https://developer.android.com/guide/components/fundament als

Babanne, V., Borgaonkar, M., Katta, M., Kudale, P., \& Deshpande, V. (2020). Emotion based personalized recommendation system. International Research Journal of Engineering and Technology (IRJET), 7(8), 701-705.

Charmy. (2021). Charmy. Retrieved from https://charmy.app/

Çümen, G. (2020). Görüntü İşleme Teknolojisi (Image Processing). Retrieved from https://medium.com/@gizemcumen $85 / \mathrm{g} \% \mathrm{C} 3 \% \mathrm{~B} 6 \mathrm{r} \% \mathrm{C} 3 \% \mathrm{~B}$ Cnt $\%$ C3\%BC-i\%CC\%87\%C5\%9Fleme-teknolojisi-imageprocessing-262bb58fbb27
Feelm. (2021). Feelm - Films for the way you feel. Retrieved from https://feelm.com/about

Flask. (2021). Foreword - Flask Documentation. Retrieved from https://flask.palletsprojects.com/en/2.0.x/foreword/

Flickseeker. (2021). Frequently Asked Questions - Flickseeker. Retrieved from https://flickseeker.com/faqs

Google Inc. (2021a). Cloud Computing Services. Retrieved from https://cloud.google.com/

Google Inc. (2021b). Cloud SQL. Retrieved from https://cloud.google.com/sql

Google Inc. (2021c). Why Google Cloud. Retrieved from https://cloud.google.com/why-google-cloud/

Mariappan, M. B., Suk, M., \& Prabhakaran, B. (2012). FaceFetch: A User Emotion Driven Multimedia Content Recommendation System Based on Facial Expression Recognition. Paper presented at the 2012 IEEE International Symposium on Multimedia.

Metilda Florence, S., \& Uma, M. (2020). Emotional Detection and Music Recommendation System based on User Facial Expression. IOP Conference Series: Materials Science and Engineering, 912.

Sharma, P. (2020). Multimedia Recommender System using Facial Expression Recognition. International Journal of Engineering Research \& Technology (IJERT), 9(5), 674-676.

Shenk, J. (2021). FER. Retrieved from https://pypi.org/project/fer/

Statista. (2019). Share of global smartphone shipments by operating system from 2014 to 2023. Retrieved from https://www.statista.com/statistics/272307/market-shareforecast-for-smartphone-operating-systems/

TMDB. (2021). API Overview - The Movie Database. Retrieved from https://www.themoviedb.org/documentation/api 